\title{
Virtuality in Human Supervisory Control: Assessing the effects of psychological and social remoteness.
}

\author{
Neville A. Stanton* \\ Department of Design \\ Brunel University \\ Runnymede Campus \\ Egham \\ Surrey \\ TW20 0JZ \\ UK
}

\author{
Melanie J. Ashleigh \\ Department of Management \\ University of Southampton \\ Highfield \\ Southampton \\ SO17 1BJ \\ UK
}

\author{
Anthony D. Roberts and \\ Francis $\mathrm{Xu}$ \\ Department of Psychology \\ University of Southampton \\ Highfield \\ Southampton \\ SO17 1BJ \\ UK
}

Virtuality would seem to offer certain advantages for human supervisory control. First, it could provide a physical analogue of the 'real world' environment. Second, it does not require control room engineers to be in the same place as each other. In order to investigate these issues, a low-fidelity simulation of an energy distribution network was developed. The main aims of the research were to assess some of the psychological concerns associated with virtual environments. First, it may result in the social isolation of the people, and it may have dramatic effects upon the nature of the work. Second, a direct physical correspondence with the 'real world' may not best support human supervisory control activities. Experimental teams were asked to control an energy distribution network. Measures of team performance, group identity and core job characteristics were taken. In general terms, the results showed that teams working in the same location performed better than team who were remote from one another.

KEYWORDS: SCADA, Human Supervisory Control, Interface Design, Team Working

*Corresponding author:

phone: +44 (0) 1784431341 ext 234

fax:+44 (0) 1784472879

email: Neville.Stanton@brunel.ac.uk 


\section{HUMAN SUPERVISORY CONTROL}

Currently control room engineers are able to control whole processes through System control And Data Acquisition (SCADA) technology. These typically combine mimic displays (to present a graphical representation of the plant process), tables of data, time-based figures and alarm lists, allowing the engineer to access vast amounts of information in various formats (Stanton \& Ashleigh 2000). Systems are currently window driven and/or menu based and the organisation of the information generally reflects the topography of the physical plant. Computer-based representation allows the engineer great flexibility in looking at the different levels of the system. Despite this, individuals may still be limited by the amount of information they can access at one time. As process control tasks are both discrete and continuous, engineers necessarily have to fluctuate between the different levels of processing (Rasmussen 1986, Vicente et al 1995). They may also have to monitor other screens displaying sequenced and alphanumeric information. Therefore as well as controlling the plant process with its many complexities and monitoring the various surveillance systems, engineers also have to cope with finding their way through the interface. Relating conventional displays back to the Levels of Absraction Hierarchy (Rasmussen 1986) model, it may be that they stand somewhere nearing the mid-point of the continuum between abstract function and the physical form. With modern technology however, it is entirely possible to represent any environment in a similar, yet entirely independent way to the physical world.

Most organisations appear to be adopting a strategy of increasing centralization. Stanton \& Ashleigh (2000) report on a study in an energy distribution company that moved from 12 control centres to four and could ultimately move to one. This has led to considerable re-organisation within the company and the effect of re-locations has undoubtedly caused some disruption to the workers and their families. The control room environment may become the model for other types of working, for example manufacturing organisations may not need constant presence of workers with increased automation and may opt for remote monitoring at some point in the future. Power generation companies already have remotely monitored gas turbine stations. Therefore, findings from research into human supervisory control may well become more widely applicable. In addition, errors in human supervisory control can have 
potentially disastrous consequences, which can impact upon the lives of many people, beyond those making the errors. This makes human supervisory control an important area of psychological research.

Virtual working environments could negate the need to physically centralize personnel as they could work remotely from each other as well as remotely from the plant they are supervising. The virtual environment could be an analogue of the elements contained in the real world. This representation may have advantages over current mimic displays, as the control room engineer could literally inspect the status of the plant (depending upon the capability of sensor technology) and operate the plant directly. Virtual technologies may also enable the control room engineer to converse directly with other engineers whilst inspecting the same plant. Errors often arise due to misunderstandings over the telephone regarding the aspect of the plant is being discussed. These errors could potentially be reduced through virtual systems. However, virtual systems may introduce new kinds of problems, such as overwhelming the operator with information. In short, it might simply be a case of replacing one set of problems with another. It has been suggested that the wealth of information might be more manageable by functional representation techniques (Praetorius \& Duncan 1991). This could reduce all system components to six basic functions. Praetorius \& Duncan (1991) claim that functional representation reduces the workload of operators and decreases fault diagnosis time considerably. Given that the energy transportation system could be represented both physically and functionally, it will be important to explore the nature of interactions between control room engineers with both systems and compare the data with conventional control systems. Whilst virtual environments offer the potential for physical 'remoteness' to be overcome there is the potential risk of the social consequences associated with the diffusion of responsibility if the control room engineers are not working in the same physical environment. Therefore the aspect of personal identity will also be a factor worthy of attention.

\subsection{Psychological remoteness}

Theoretical contributions in Human Supervisory Control have largely centred around models of the human operators (Rasumssen 1974, Stammers \& Hallam 1985, 
Hollnagel 1993, Stanton et al 2001) and their interaction with automated systems (Bainbridge 1987, Reason 1990, Norman 1990). This presents an interesting research paradigm in which to consider the degree of control, and sometimes lack of control, that human operators have over dynamic, complex, and closely coupled systems (Perrow 1984).

In order to discuss supervisory control at this higher level it is appropriate to return to the LOAH model (Rasmussen 1986) and re-consider this framework and its relevance to the human-machine interaction process generally. The levels of abstraction can be used as a hierarchical representation which characterizes the different stages of human decision making in supervisory control; describing how the operator moves translate concrete physical appearance of system components to goal-seeking functional purposeful objectives whilst interacting with the system. It can also be used as a representation of the physical and functional parts of a plant; the systems and components. At the most basic level, the structure in its Physical form is characterized by a static picture spatially described in physical terms. At the Physical function level, although the physical objects are still the main component, there is an interaction with their level of function. The Functional structure is more directly representative of the process rather than physical objects, and the structure reflects selected elements of its behavioural process. At the Abstract function level the system can be described at a more symbolic level where it depicts the general flow of a system, for example in energy or mass terms. The Functional meaning level describes the relationship between the states and events within the systems environment and is connected with the definition of system goals such as balance, security and efficiency. As systems have necessarily become more complex and multi-layered, design technology in developing current interfaces have necessarily had to compromise between the physical form and functional purpose. However as already indicated, engineers may shift levels of cognitive control depending on the situation (Vicente et al 1995). In doing so, it may be that the requirement to convert process objectives into physical plant manipulations exerts an added cognitive load on to the operators task (Rasmussen 1986).

In could be argued that a system which presents virtual representations of real objects 
in the environment may be easier for human processes operators to control. This could provide the operators with a natural view of the plant and other team members, through the concept of virtual reality. It might be argued that people are already controlling plant virtually, and that simply increasing the bandwidth in the channel may not have any advantages; indeed operators may feel more disadvantaged or even disorientated. Alternatively, presenting a high level of abstraction of the system, by means of symbols and signs representing functions, may prove to simpler to operate. A host of questions and related problems face us in this task and the answers still remain to be determined.

Valuable research has also been carried out to optimize interface design that assists control engineers to attend to the increasing amount of data provided. This is a particular problem in the aviation industry as technology aims to simultaneously increase automation and pilot control. It is considered that by reducing the number of displays that represent the integration of several variables into one single interface, not only saves space but is thought to make more efficient use of pilot attentional resources, (Greaney \& MacRae 1996). Specifically, the use of polygons is seen as being a superior form of display, not only for multiples of integrated variables but because they can be processed in parallel rather than as individual variables (Jacob et al 1976). Barnett \& Wickens (1988) also found that polygons were better than conventional displays in fault diagnosis. Research by Munson \& Horst (1986) supported this finding. They used polygons to display normal and abnormal states. They found that reaction times decreased when more axes were present, concluding that polygons were processed in parallel, equivalent to holistically. More recent research (Greaney \& Macrae 1996) used a set of three separate polygon formats (standard, fixed and outwards) displaying up to 18 different parameters to test the presence or absence of a fault state, errors and number of parameters out-of-limits using reaction times. Results showed that performances increased in all three conditions as the number of parameters increased, and the outward format was found to be the most effective. Although this supported the use of polygons as suitable displays to detect the presence of abnormalities at a glance, the speed of locating where each fault lies in any system is equally important to any human supervisory control task (Woods et al 1981). The advantage of using polygons is that as the 
parameters change, this causes another emergent shape, which could make failure or fault diagnosis easier.

\subsection{Social remoteness}

Research into the effects of physical proximity on team performance has come from both communication research and social psychology. Much of the early communication research used idea generation tasks to compare the performance of face to face groups interacting together, with that of nominal groups (individuals working separately without communicating whose ideas were later pooled). There is an intuitive appeal that interacting groups will perform better than nominal groups because they benefit from mutual stimulation, learning, piggybacking and synergy to produce large numbers of potentially novel and valuable ideas, (Valacich et al 1994). However a literature review by McGrath (1984) found that individuals working separately generated many more ideas, and more creative ideas despite the lack of perceived benefits of interaction. It has been suggested that this finding may be explained in terms of the processes losses of group interaction (Steiner 1972), such as production blocking, free-riding, and evaluation apprehension, (Diehl \& Stroebe 1987).

Production blocking occurs in oral communication (e.g. face-to-face, telephone) because only one person can speak at a time. Similar effects may also be found with verbal electronic text mediums where the software only permits synchronous communication, i.e. limits communication to one speaker at a time. Group members are prohibited from verbalizing their ideas as they occur and may later forget them or suppress them because they seem less original or relevant (Diehl \& Stroebe 1987). Alternatively the very act of sitting and listening to other's ideas may be distracting and interfere with the ideas process. Diehl and Stroebe (1987) found a strong effect of production blocking in an idea generation task. Their findings suggested that this was not due to forgetting or suppressing ideas, but rather that the periods of blocking prevented the development of new thoughts due to the competing demands of resources in short term memory.

Physical proximity also influences communication methods. When teams are 
separated by physical distance decision making can breakdown. Wellens (1993) proposed that the communication media were crucial elements in creating the necessary 'linking bridge' that allowed distributed decision making units to develop a sense of group situational awareness that would ultimately affect the decision made. Although various electronic tools have aided in the process of replacing the distancing barrier, there are apparent differences in the amount of information, or bandwidth, associated with specific technologies and how they compare with face to face communications. Wellens (1993) proposed a model of 'psychological distancing', based on the proximity premise that the further away the physical representation (i.e. from face to face) so the narrower the bandwidth, and the more psychologically remote team members feel when trying to collaborate.

\subsection{Remoteness from people and tasks}

One way of interpreting the effects of psychological and social remoteness is through the 'Core Job Characteristics' model (Hackman \& Oldham 1980). This model identifies five principle characteristics of work that predict job performance and satisfaction. The model has received considerable support in the academic literature (e.g. Hogan \& Martell 1987, Champoux 1991). The core job characteristics are: skill variety (the degree to which the job challenges a person to use a range of skills and abilities), task identity (the degree to which the job results in an identifiable and visible outcome), task significance (the degree to which the job has a perceivable impact upon others), autonomy (the degree to which the job provides the individual with freedom and discretion in scheduling work and how it will be undertaken) and feedback (the degree to which the individual is provided with information about the effectiveness of their efforts). These characteristics are determined from a self-report questionnaire (Hackman \& Oldham 1980). It is envisaged that virtual environments could have a dramatic effect upon the psychological aspects of work, and this should certainly be explored.

Hackman \& Oldham (1980) report research on the necessary psychological states that an individual should experience in order to determine motivation and satisfaction.

These were:

- Experienced meaningfulness - where the person perceives their work as 
worthwhile by an acceptable value system

- Experienced responsibility - where belief exists that an employee is personally accountable for the outcome of effort.

- Knowledge of results - where there is regular opportunity for the individual to know how satisfactory their work is.

From this they identified five core job dimensions that could determine how ‘internally motivated’ and consequently more satisfied people were:

1. Skill variety - the degree to which the job challenges a person to use a range of skills and abilities

2. Task identity - the degree to which the job results in an identifiable and visible outcome

3. Task significance - the degree to which the job has a perceivable impact upon others.

4. Autonomy - the degree to which the job provides the individual with freedom and discretion in scheduling work and how it will be undertaken.

5. Feedback - the degree to which the individual is provided with information about the effectiveness of their efforts.

It is envisaged that changes in technological interfaces within supervisory control, may in fact have an impact on the intrinsic motivational nature of the job. It is therefore intended to explore the intrinsic value of operator's work, when the workdomain environment is represented in two dichotomous forms. Virtuality may affect people's perception of job meaningfulness, responsibility or feedback in a number of ways either positively or negatively. For example, it may be more difficult for people to see the impact their job has on others (task significant) or for them to see the outcome of their efforts (task identity).

According to Annett \& Stanton (2000), the main design issues in contemporary team working research are the structure of the team, training of the team, and development of the human-machine interface. This paper proposes to address the first and third issues. Carletta et al (2000) present an optimistic picture for virtual team work. They 
suggest that a relatively modest level of technology can support collaborative working, despite the non co-location of people. They do point out however, that virtual team working may affect the dynamics of the team and practical issues, such as turn-taking in discussions, need to be resolved. This may require new ways of thinking about the design of interface technologies, to support collaborative decision making by team members who are no longer co-located. Two opposing themes for interface design are to either opt for a physical analogue of the real world or to opt for a goal-oriented, functional, abstraction of it (Rasmussen, 1986). Both of these design themes are investigated in the empirical study.

Specifically the research addressed the following questions:

- Are there performance gains associated with portraying a human supervisory control environment functionally rather than physically?

- What are the effects of virtuality on the Core Job Characteristics? (e.g. the perception of job satisfaction developed from Hackman \& Oldham’s model)

- To what extent is it important to preserve personal identity in a virtual environment?

\section{METHOD}

The experimental method used in the main study is as follows.

\subsection{Participants}

A total of 96 participants took part in this study. They were recruited via email and poster notices distributed around the University of Southamton. Participants were aged from 19 to 55; with a range of 36 years, the mean age being 26. The sample consisted of 74 males and 22 females.

\subsection{Design}

The study was designed to test the effects of location and interface type on teams working in a simulated controlled environment. There were 24 groups of 4 people used in the study, separated into the four different experimental groups (e.g. virtualdistal, virtual-proximal, abstract-distal, abstract-proximal). No significant differences in distribution of gender were found. The dependent variables were as follows: 
- Number of control actions (total number of control actions each team used).

- Cost (how much did it cost each team to run their network and how far away the teams were from the optimum cost).

- Group Identity (Watt \& Spears1999, a measure of group identity and cohesiveness).

- Core Job Characteristics (Hackman \& Oldham 1980, a measure of intrinsic job motivation).

\subsection{Equipment}

Four networked personal computers were used for the laboratory-based experiments. Each team member used a PC with either a virtual or abstract interface that represented

a geographical area gas network, (e.g. North, South, East or West). Video cameras were used in each laboratory to allow visual communication across the distal condition. Telephones were used in the distal condition to enable communication amongst the team members. The software used to develop the two interfaces was World Tool Kit. The software package Falcon was adapted and used to form the link from the server to the four networked machines

Each team member was provided with a set of instructions explaining what the task consisted of and how to complete it. These were altered slightly, dependent upon the condition people were in (e.g. virtual, abstract, distal, proximal). In addition, each participant had a user guide of the interface. Participants were also provided with instructions for completing the questionnaires, which were all computer based. Questionnaires included a biographical survey, the Core Job Characteristics survey (Hackman \& Oldham 1980), and a Social Identity survey (Watt \& Spears 1999). Participants were also asked to complete a consent and ethical form and receipt for payment.

\subsection{Experimental task}

The overall aim of the task was to operate a gas network so that all of the operational demands are met (e.g. the system input-output remains in balance, system pressures are kept within tolerances and that operating costs are kept as low as possible). The 
network supplies four areas and each area was operated by an experimental participant. The gas is supplied to each area at a constant rate through a regulator. All areas have a working pressure range of between 10 bar and 38 bar.

The main objectives of the task were to:

- minimize overall flow-rate variation

- keep all pressures above 10 bar and below 38 bar

- operate system as close to 10 bar as possible

- minimze the use of the holder

- make sure that end of day stock was the same as start of day stock

Although the gas is supplied at a constant rate, the gas consumers on the do not take gas out the network at a constant rate. As demand can change at anytime, and the participant will only become aware of the change after it has happened, they need to be able to respond quickly. If demand is greater than supply then additional gas can be taken from line pack (i.e. high-pressure pipes), the holder (i.e. a gas storage facility), and by increasing supply through the regulator. If demand is lower than supply then surplus gas has to be stored as line pack or in the holder, or supply has to be decreased through the regulator.

When it comes to making the changes, each participant has a choice of either acting alone or acting in co-ordination with the other team members. Optimal solutions to the problems they were set come from a co-ordinated effort because adjustments to the overall flow-rate of gas supplying the four areas had heavy financial penalties. Only by co-ordinating flow-rate changes with other areas could participants minimize or prevent overall flow-rate changes.

\subsection{Procedure}

The experimental procedure was as follows:

(i) Participants were recruited in teams of four.

(ii) They were introduced to each other and given an initial introduction and briefing about the task. 
(iii) Ethical matters were explained and the consent form was signed.

(iv) Biographical data were collected and each member was told which condition they were being tested in (i.e. abstract/virtual, proximal/distal) and given an identification name (e.g. North South, East or West).

(v) They were then given their instructions and given a hands-on demonstration of how to control the gas network.

(vi) Participants undertook a one-hour training session before performing the task. All participants were given one-to-one assistance throughout this training

(vii) The team was asked to carry out the task with no assistance from the researchers. All participants were asked to work together as a team. The experimental phase lasted approximately one hour.

They were then paid $£ 10$, asked to sign a receipt and were thanked for their time and participation.

\subsection{Analysis}

A variety of statistical techniques were used to analyse the data. Comparison of the experimental groups through the two main independent variables (i.e. proximity and interface) relied upon Analysis of Variance (ANOVA). Factor analysis was used to determine the factor structure of the social identity questionnaire. Then ANOVA was conducted on the factor scores.

\section{RESULTS}

The results of the experiment are reported in the following sections, comprising: control actions, costs, social identity, and core job characteristics.

\subsection{Control actions}

Analysis of the control actions considered the number of times each of the groups changed the regulator, filled the holder, emptied the holder, and stopped using the holder. There were no statistically significant main effects in the control actions for changing the regulator $\left(\mathrm{F}_{3,20}=0.214 ; \mathrm{p}=\mathrm{NS}\right)$. There were no statistically significant main effects in the control actions for filling the holder either $\left(F_{3,20}=0.36 ; p=N S\right)$. Nor were there any statistically significant main effects in control actions for stopping the 
holder $\left(\mathrm{F}_{3,20}=1.148 ; \mathrm{p}=\mathrm{NS}\right)$. As figure 1 shows, there appears to be a difference in the control actions for emptying the holder in the abstract group than in the virtual group, particularly in the distal condition $\left(\mathrm{F}_{1,20}=4.109 ; \mathrm{p}<0.057\right)$, which approaches statistical significance. There were no interaction effects.

\section{FIGURE ONE ABOUT HERE}

\section{Figure 1. Mean number of control actions for emptying the holder}

\subsection{Costs}

Optimum costs were subtracted from actual costs to determine how far each group was away from their target. The results for the four experimental groups are shown in figure 2 .

\section{FIGURE TWO ABOUT HERE}

Figure 2. Mean difference between optimum and actual team costs

As figure 2 shows, there was a in the greater discrepancy between the actual and optimum costs in the distal condition compared to the proximal condition, and this was statistically significant main effect $\left(\mathrm{F}_{1,20}=5.605 ; \mathrm{p}<0.05\right)$. This means that the teams in the proximal condition were far more efficient at running the system than for those in the distal condition. There were no interaction effects. 


\subsection{Social identity}

The data from the social identity questionnaire were analysed to determine the factor structure. The scree-plot suggested that two factors should be extracted. The varimax rotated solution shows that factor 1 (group identity) comprised of items 1, 4, 5, 6, 7, 9, 10, and 12, whereas factor 2 (cohesiveness) comprised of items 2, 8, and 11. Analysis was performed on the factor scores as this indicates the extent to which each participant's behaviour has been affected by that factor.

For the group identity, there was a statistically significant difference between the two different interfaces $\left(\mathrm{F}_{1,92}=10.091 ; \mathrm{p}<0.005\right)$ and an interaction between interface and proximity $\left(\mathrm{F}_{1,92}=4.871 ; \mathrm{p}<0.05\right)$. These effects are illustrated in figure 3 .

\section{FIGURE THREE ABOUT HERE}

\section{Figure 3. Mean group identity scores for the experimental conditions}

As figure 3 shows, the group identity scores were higher for the abstract group. Also the virtual group scores were lower in the distal condition than the proximal condition.

For the cohesiveness, there was a statistically significant interaction between interface and proximity $\left(\mathrm{F}_{1,92}=37.084 ; \mathrm{p}<0.001\right)$. These effects are illustrated in figure 4 .

\section{FIGURE FOUR ABOUT HERE}

\section{Figure 4. Mean cohesiveness scores for the experimental conditions}

As figure 4 shows, the cohesiveness scores were higher for the abstract group in the distal condition, whereas the virtual group scores were higher in the proximal condition than the distal condition. 


\subsection{Core job characteristics}

The core job characteristics model of intrinsic job motivation, comprises seven main areas: skill variety, task identity, task significance, autonomy, feedback from the job, feedback from others, and dealing with others.

For skill variety, there was a statistically significant difference between the proximity conditions $\left(\mathrm{F}_{1,92}=44.328 ; \mathrm{p}<0.001\right)$ as shown in figure 5. This means that participants rated their skill use as more varied in the proximal condition those in the distal condition.

\section{FIGURE FIVE}

\section{Figure 5. Mean skill variety scores for the experimental groups}

There were no statistical differences between the experimental groups for task identity, task significance, and autonomy. For feedback from the job, there was a statistically significant difference between the interface groups $\left(\mathrm{F}_{1,92}=19.272\right.$; $\mathrm{p}<0.001)$, proximity conditions $\left(\mathrm{F}_{1,92}=8.961 ; \mathrm{p}<0.005\right)$, and interaction between interface groups and proximity conditions $\left(\mathrm{F}_{1,92}=7.806 ; \mathrm{p}<0.01\right)$. These effects are illustrated in figure 6.

\section{FIGURE SIX ABOUT HERE}

\section{Figure 6. Mean feedback from the job scores for the experimental groups}

As figure 6 shows, feedback from the job was rated higher by the abstract groups than the virtual groups, and the abstract groups in the proximal group rated feedback from the job higher than the abstract groups in the distal condition. This means that feedback from the job is perceived at its highest in the abstract-proximal condition. 
For feedback from others, there was a statistically significant difference between the interface groups $\left(\mathrm{F}_{1,92}=29.885 ; \mathrm{p}<0.001\right)$, proximity conditions $\left(\mathrm{F}_{1,92}=13.058\right.$; $\mathrm{p}<0.001$ ), and interaction between interface groups and proximity conditions $\left(\mathrm{F}_{1,92}=10.517 ; \mathrm{p}<0.005\right)$. These effects are illustrated in figure 7. 


\section{FIGURE SEVEN ABOUT HERE}

\section{Figure 7. Mean feedback from others scores for the experimental groups}

As figure 7 shows, feedback from others was rated higher by the abstract groups than the virtual groups, and the abstract groups in the proximal group rated feedback from others higher than the abstract groups in the distal condition. This means that feedback from others is perceived at its highest in the abstract-proximal condition.

There were no statistical differences between the experimental groups for dealing with others. The motivating potential score (MPS: a value to represent the intrinsic motivation of the job) was calculated for participants using the following formula:

MPS $=($ skill variety + task identity + task significance /3 $) \mathrm{x}$ autonomy $\mathrm{x}$ feedback

The mean scores for four experimental groups are presented in figure 8.

\section{FIGURE EIGHT ABOUT HERE}

\section{Figure 8. Mean MPS for the experimental groups}

As figure 8 shows, the scores are significantly higher in the proximal condition $\left(\mathrm{F}_{1,92}=4.434 ; \mathrm{p}<0.05\right)$. This means that the participants in the proximal condition report higher levels of intrinsic motivation with the task than those in the distal condition.

\subsection{Summary of results}

The results are summarized in table 1. In general terms, the proximal condition is favoured over the distal condition and the abstract condition is favoured over the distal condition, although this is not always the case. 
TABLE ONE ABOUT HERE

\section{Table 1 . Summary of statistically significant results}

\section{DISCUSSION}

The findings from this research are interpreted in the context of the research literature. First the reasons why the proximal condition was superior will be discussed under the heading of virtual teams. Second, the differences between the abstract and virtual interfaces will be explored under the heading of virtual interfaces.

\subsection{Virtual teams}

The results suggest that the proximal condition was superior to the distal condition in terms of reduced costs, greater group identity, enhanced motivation and greater tactical control. There is an intuitive appeal that people will perform better if they are located in the same physical proximity because they benefit from mutual stimulation to produce large numbers of potentially novel and valuable ideas (Valacich et al 1994). Individuals behaviour may be enhanced by the simple physical presence of others, independent of any information or interaction influences these others may exert (Sanders 1981). Although a large number of studies have investigated the effects of the physical presence of others on task performance, the findings are still contradictory. In some studies, an individual's performance was enhanced whilst in others it was impaired (Sanders 1981). It is likely however, that many of these studies have been confounded by the wide variety of tasks that have been used as part of their methodology. Sanders (1981) clarified some of this confusion with the proposal that the effect of the presence of others on performance was dependent on the nature of the task. When the task was simple or well learned the presence of others enhanced performance, whilst for complex or novel tasks performance was impaired. In the current study, team co-operation was essential for good performance. Working in the same room as the other team members maybe conducive to co-operative tasks particularly as it encourages informal communication. 
Kraut et al (1990), have stressed the importance of informal communication in group interactions. Informal communication is a loosely defined concept, but may be thought of as unscheduled communication, between random participants with no prearranged agenda, that is highly interactive and rich. In a study of a research and development organization. Kraut et al (1990) found that 85\% of all communication was informal, of which $50 \%$ occurred because colleagues were physically proximate. After interviewing those involved in informal communication episodes they found that as the opportunity for informal communication with colleagues increased so did familiarity with them and their work, and liking for them and their work. They concluded that proximity leads to increased frequency of communication in general, and of informal communication specifically. Proximate colleagues have more opportunity for spontaneous conversations, which lead to greater familiarity and increased respect. They propose it is therefore likely to be a powerful facilitator for successful working relationships, since familiarity will enable them to share perspectives. Physical proximity helps by allowing appropriate people to encounter one another frequently, by supporting visual channels (e.g. they can see each others data directly if they wish) to induce and assess readiness for communication and by supporting highly interactive communication. In this study, six of the twelve groups in the distal condition had periods when there was no interaction between the team members whereas none of the groups in the proximal condition had periods without any communication.

Effective communication also appears to play a key role in achieving team situational awareness. Salas et al (1995) report that the level of situational awareness is related to the level and quality of communication of teams. Therefore, the close proximity of the participants may have enhanced communication, giving rise to increased situational awareness. This may also have led to greater social identity and motivation.

\subsection{Virtual interfaces}

The findings of the relative superiority of the interfaces were less clear than that of proximity. For control actions and costs there were no differences between the abstract and virtual interface groups. This means that both groups faired as well as 
each other. There are differences however, between the interface groups for the psychological measures of social identity and core job characteristics.

The literature confirmed that polygon displays make more efficient use of attentional resources (Greaney \& MacRae 1996), are better for fault diagnosis than conventional displays (Green et al 1996, Barnett \& Wickens 1988, Munson \& Horst 1986, Woods et al 1981), provide an integrated and compact display (Green et al 1996) and are processed holistically (Jacob et al 1976). These claims are made for a wide range of applications including nuclear power, intensive treatment units, and aviation. Given this evidence, it is perhaps surprising that there were no performance differences between the virtual and abstract groups in the energy distribution network task. This may be due, in part, to the relatively small number of groups tested. The polygon displays used in the experiment described in this paper differ from those in previous studies. The difference in this study was that predictive data about the status of the system at the end of the shift were provided, rather than concurrent data of system performance. This type of information was consistent with the strategy of presenting goal-oriented data in line with the higher levels of the LOAH framework (Rasmussen 1986) and distinguishes this study from those that have come before it.

The differences in social identity and core job characteristics found in this research may be traceable to the nature of the information presented to participants. Providing the participants with predictive information about the consequences of their actions helps provide feedback from the job. This in turn could enhance feedback from the other team members about progress towards the team goals. This may have, in turn, improved each of the team member's perception of group identity. The interaction between the type of interface and team proximity revealed that feedback (both from the job and other people) was rated as highest in the abstract-proximal group. The goal-oriented displays probably helped promote discussion between team members. It is argued that polygon displays are more easily understood and facilitate decision making (Green et al 1996), which may have presented the abstract group with an advantage. 


\section{CONCLUSIONS}

In summary, this research project has shown that the proximity of team members is important for improving the cost-effectiveness of system control, increasing group identity and intrinsic motivation. Abstract interfaces are associated with higher levels of feedback from the job and others as well as higher levels of social identity. From this research it may be concluded that it is preferable to have control room teams working in the same room and that abstract interfaces can help with some aspects of feedback which may assist in developing group identity. Virtual displays did not, however, lead to less efficient ways of working, as measured by costs in this study.

\section{ACKNOWLEDGEMENTS}

This research project was supported by funding made available through the ESRC's Virtual Society programme (grant reference: L132251038).

\section{REFERENCES}

ANNETT, J. AND STANTON, N. A. (2000) Team work - a problem for Ergonomics? Ergonomics 43, 1045-1051

BAINBRIDGE, L. (1987) Ironies of automation. In: New technology and human error. J. Rasmussen, K. Duncan AND J. Leplat. (eds.) (Chichester: Wiley), 276-283.

BARNETT, B.J. AND WICKENS, C.D., (1988), Display proximity in multicue information: the benefits of boxes, Human Factors, 30, 15-24

CARLETTA, J., ANDERSON, A. H. AND CEWAN, R. M. (2000) The effects of multimedia communication technology on non-collocated teams: a case study. Ergonomics 43, 1237-1251.

CHAMPOUX, J. E. (1991) A multivariate test of the job characteristics theory of work motivation. Journal of Organizational Behavior, 12, 431-446.

DIEHL, M. AND STROEBE, W. (1987). Productivity loss in brainstorming groups. Towards the solution of a riddle. Journal of Personality and Social Psychology, 53,(3) 497-509

GREANEY J., AND MACRAE, A.W., (1996), 'Diagnosis of fault location using polygon displays'. Ergonomics, 39, 400-411

GREANEY J., LOGIE, R. H., GILHOOLY, K. J. ROSS, D. G. AND RONALD, A. (1996), Aberdeen polygons: computer displays of physiological profiles for intensive 
care. Ergonomics, 39, 412-428

HACKMAN, J.R. AND OLDHAM, G. (1980) Work Redesign. (Reading, MA: Addison-Wesley)

HOGAN, E. A. AND MARTELL, D. A. (1987) A confirmatory structural equations analysis of the job characteristics model. Organizational Behavior and Human Decision Processes, 39, 242-263.

HOLLNAGEL, E. (1993) Human Reliability Analysis Context and Control. (London: Academic Press)

JACOB, R.J.K., EGETH, H. E. AND BEVAN, W., (1976) The face as a data display, Human Factors, 18, 189-200.

KRAUT, R.E. FISH, R.S. ROOT, R.W. AND CHALFONT, B.L. (1990). Informal communication in organisations: form, function, and echnology. In: S. Oskamp, AND S. Spacapan. (Eds). Peoples Reactions to Technology. In Factories, Offices and Aerospace. The Claremont Symposium on Applied Social Psychology. (London : Sage Publications), 145-199.

McGRATH, J. E. AND HOLLINGSHEAD, A. B. (1994) Groups Interacting with Technology. (London: Sage Publications)

MUNSON, R.C. AND HORST, R.L., (1986), Evidence for global processing of complex visual display, in Proceedings of the Human Factors Society $30^{\text {th }}$ Meeting, (Santa Monica : Human Factors Society), 776-780

NORMAN, D.A.(1990), The 'problem' with automation: inappropriate feedback and interaction, not 'over automation' In: D.E. Broadbent, A. Baddeley AND J.T. Reason (eds.) Human Factors in Hazardous Situations, (Oxford: Clarendon Press), 137-145.

PERROW, C. (1984) Normal Accidents: Living with High Risk Technology. (New York: Basic Books)

PRAETORIUS, N. AND DUNCAN, K.D., (1991). Flow representation plant processes for fault diagnosis. Behaviour and Information Technology, 10, 41-52

RASMUSSEN, J. (1974) The human data processor as a system component. Bits and pieces of a model, Riso-M-1722. (Roskilde, Denmark: Riso National Laboratory)

RASMUSSEN, J. (1986) Information Processing and Human-Machine-Interaction An Approach to Cognitive Engineering (Amsterdam: North Holland).

REASON, J. (1990) Human Error. (Cambridge: Cambridge University Press).

SALAS, E., PRINCE, C., BAKER, D.P. AND SHRESTHA, L. (1995). Situation awareness in team performance - implications for measurement and training. Human Factors 37, 123-136. 
SANDERS, G.S. (1981). Driven by distraction: an integrative review of social facilitation theory and research. Journal of Experimental Social Psychology 17, 227251.

STAMMERS, R. B. AND HALLAM, J (1985) Task allocation and the balance of load in the multiman-machine system: some case studies. Applied Ergonomics, 16, 251-257.

STANTON, N. A. AND ASHLEIGH, M. J. (2000) A field study of team working in a new human supervisory control system. Ergonomics , 43, 1190-1209.

STANTON, N. A., ASHLEIGH, M. J., ROBERTS, A. D. AND XU, F. (2000) Testing Hollnagel's contextual control model: Assessing team behaviour in a human supervisory control task. International Journal of Cognitive Ergonomics , 5, 21-33.

STEINER, I.D. (1972) Group Process and Productivity. (New York: Academic Press).

VALACICH, J.S., GEORGE, J.F., NUNAMAKER, J.F. AND VOGEL, D.R. (1994). Physical proximity effects on computer mediated group idea generation. Small Group Research, 25, 83-104.

VICENTE, K.J., CHRISTOFFERESEN, K., AND PEREKLITA, A. (1995), Supporting operator problem solving through ecological interface design. IEEE Transactions on Systems, Man and Cybernetics, 25, 529-545.

WATTS, S. AND SPEARS, R. (1999) personal communication.

WELLENS, A.R. (1993) Group situation awareness and distributed decision making: From military to civilian applications. In (eds.): J. Jr. Castillian Individual and Group Decision Making, Current Issues. (Hillsdale, NJ: Lawrence Erlbaum) 267-283.

WOODS, D., WISE., J. A., AND HANES, L. (1981). An evaluation of nuclear power plant safety parameter display systems. In: R.C. Sugarman (ed.), Proceedings of the $25^{\text {th }}$ Annual Meeting of the Human Factors Society. (Santa Monica, CA: Human Factors Society), 110-114. 


\section{List of tables}

Table 1. Summary of statistically significant results

\section{List of figures}

Figure 1. Mean number of control actions for emptying the holder

Figure 2. Mean difference between optimum and actual team costs

Figure 3. Mean group identity scores for the experimental conditions

Figure 4. Mean cohesiveness scores for the experimental conditions

Figure 5. Mean skill variety scores for the experimental groups

Figure 6. Mean feedback from the job scores for the experimental groups

Figure 7. Mean feedback from others scores for the experimental groups

Figure 8. Mean MPS for the experimental groups 


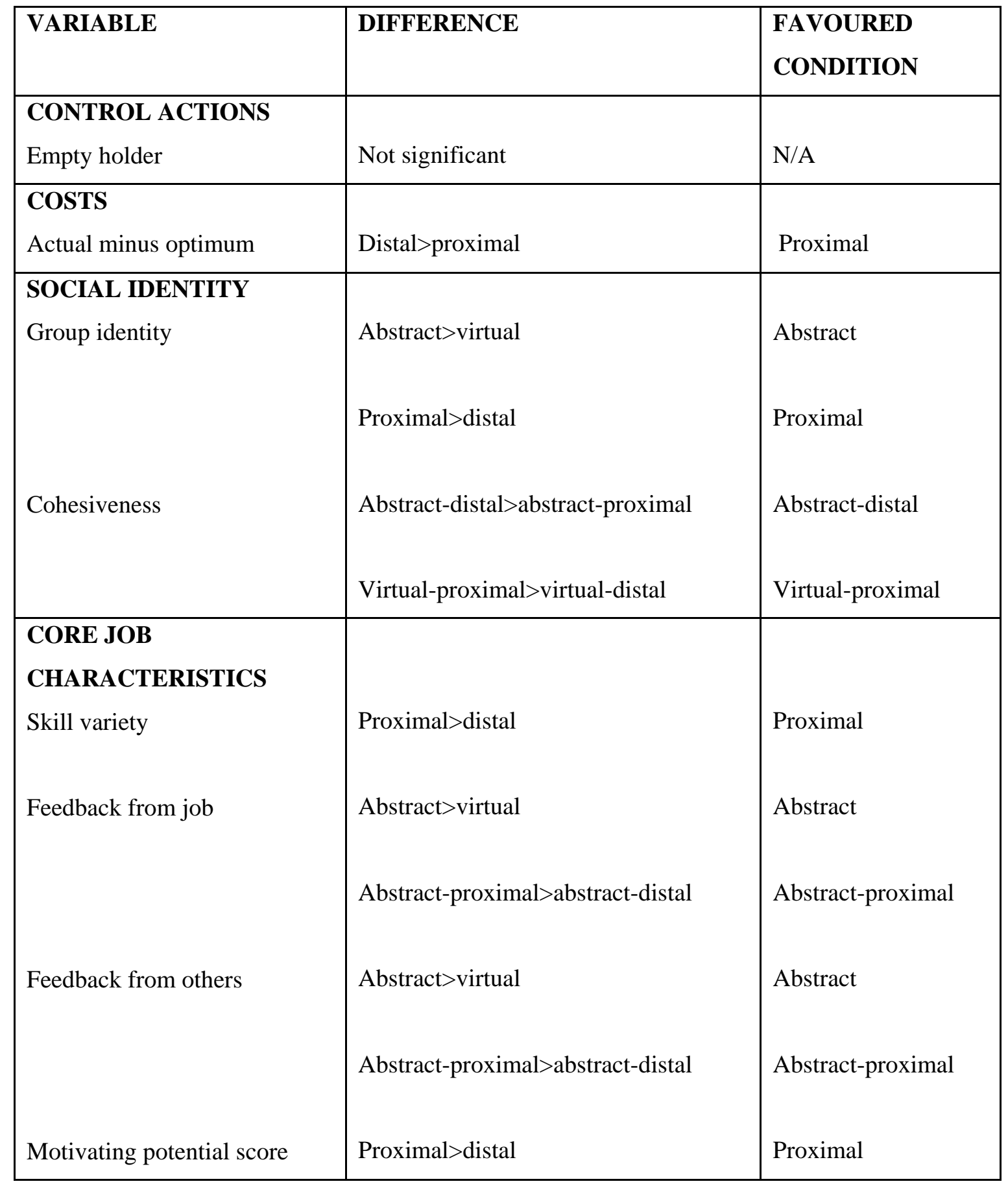


Table 1. Summary of statistically significant results 


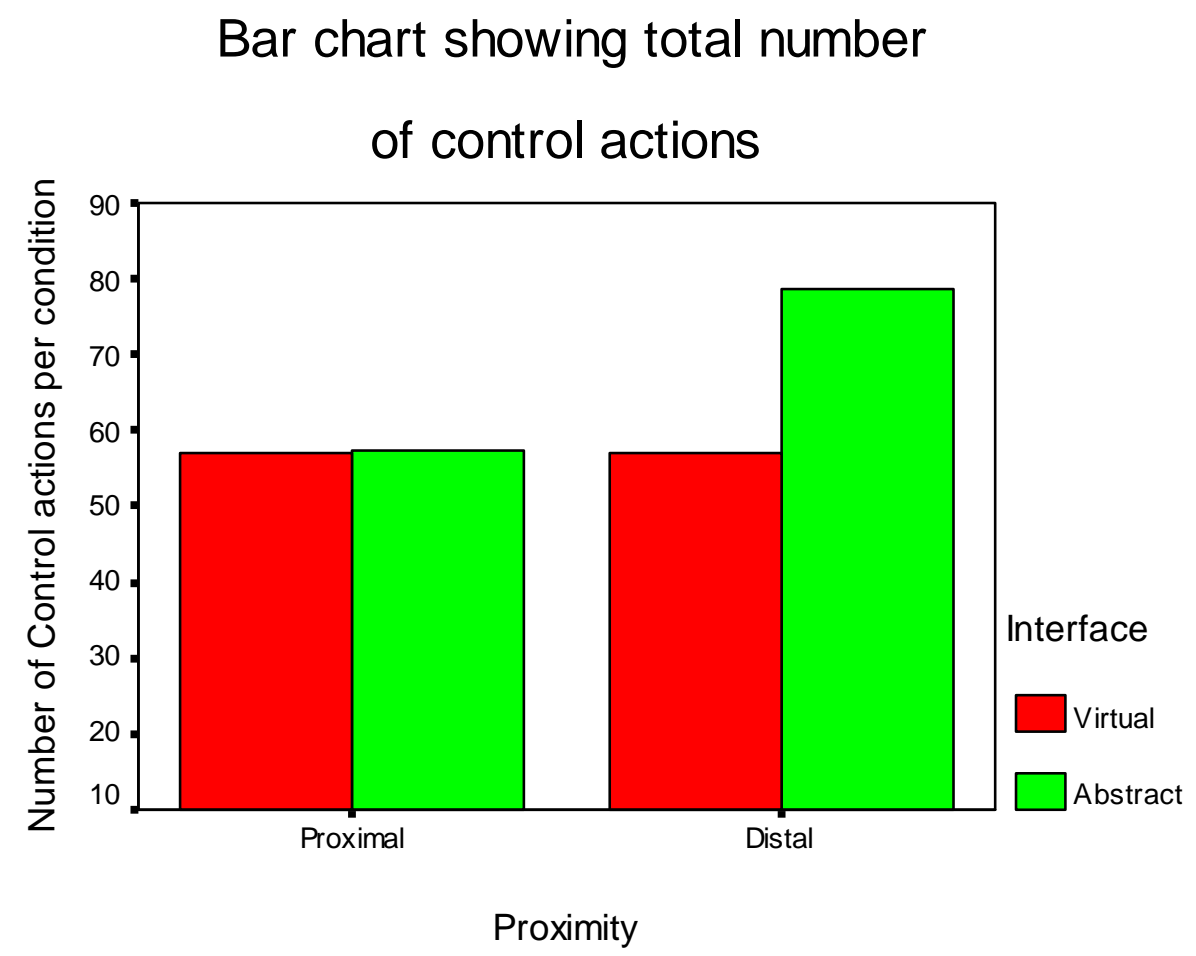

Figure 1. Mean number of control actions for emptying the holder 


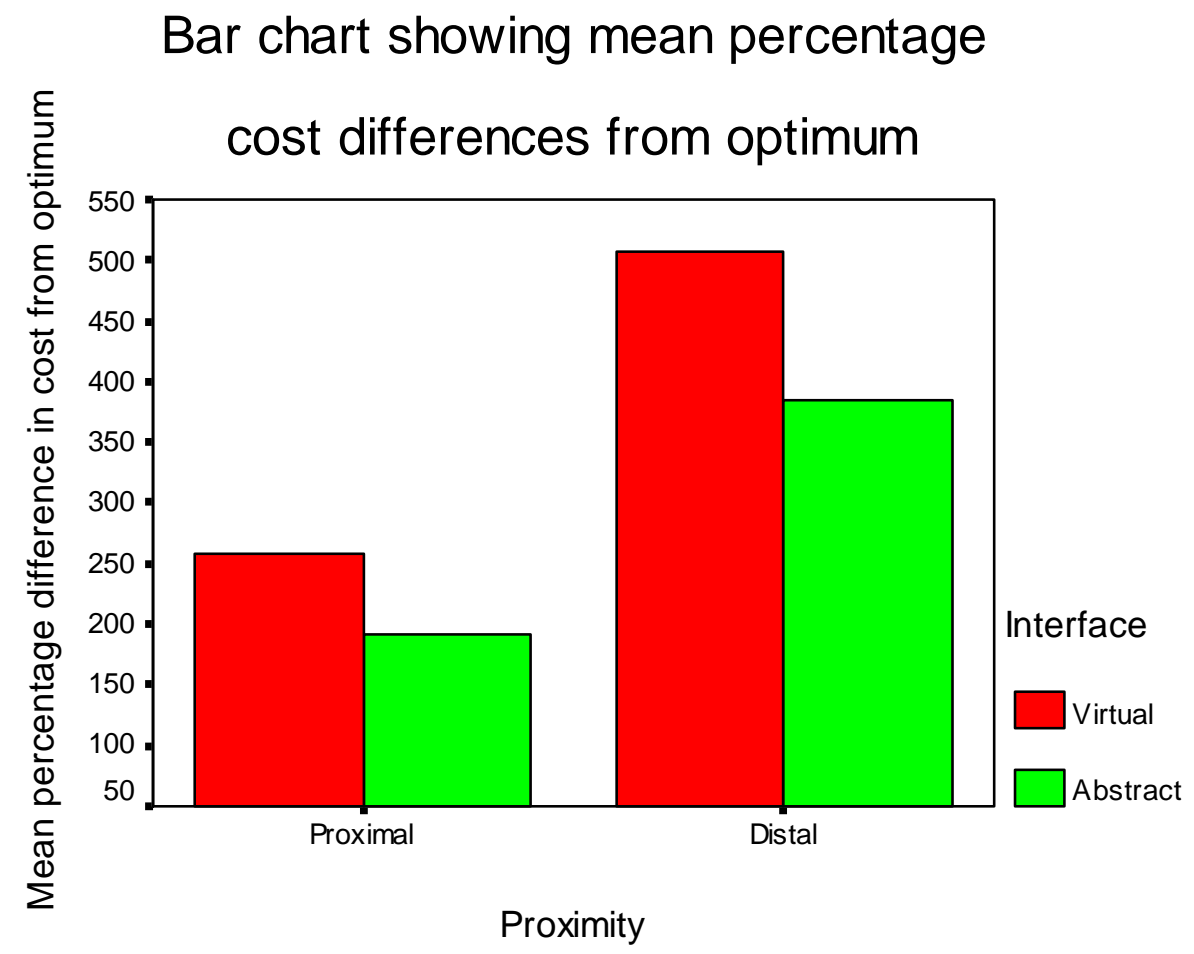

Figure 2. Mean difference between optimum and actual team costs 


\section{Bar chart showing mean factor scores}

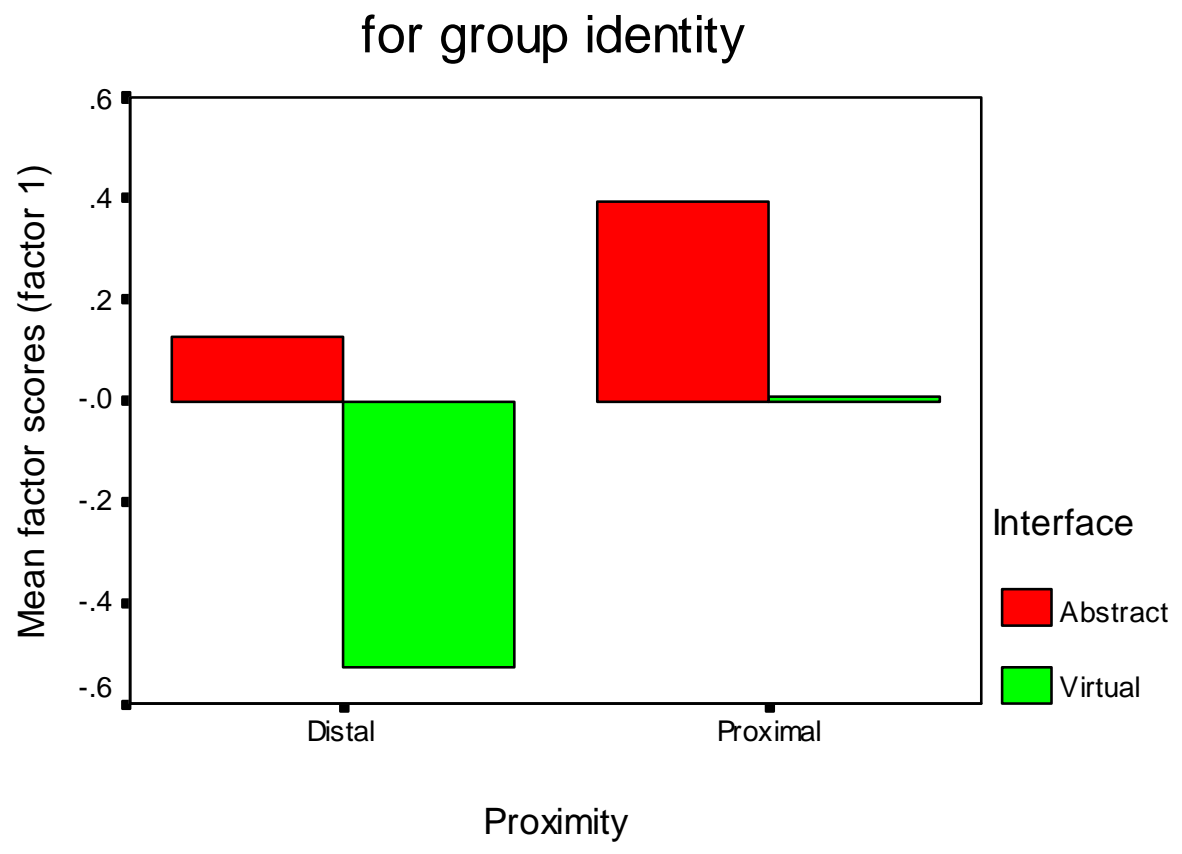

Figure 3. Mean group identity scores for the experimental conditions 


\section{Bar chart showing mean factor scores}

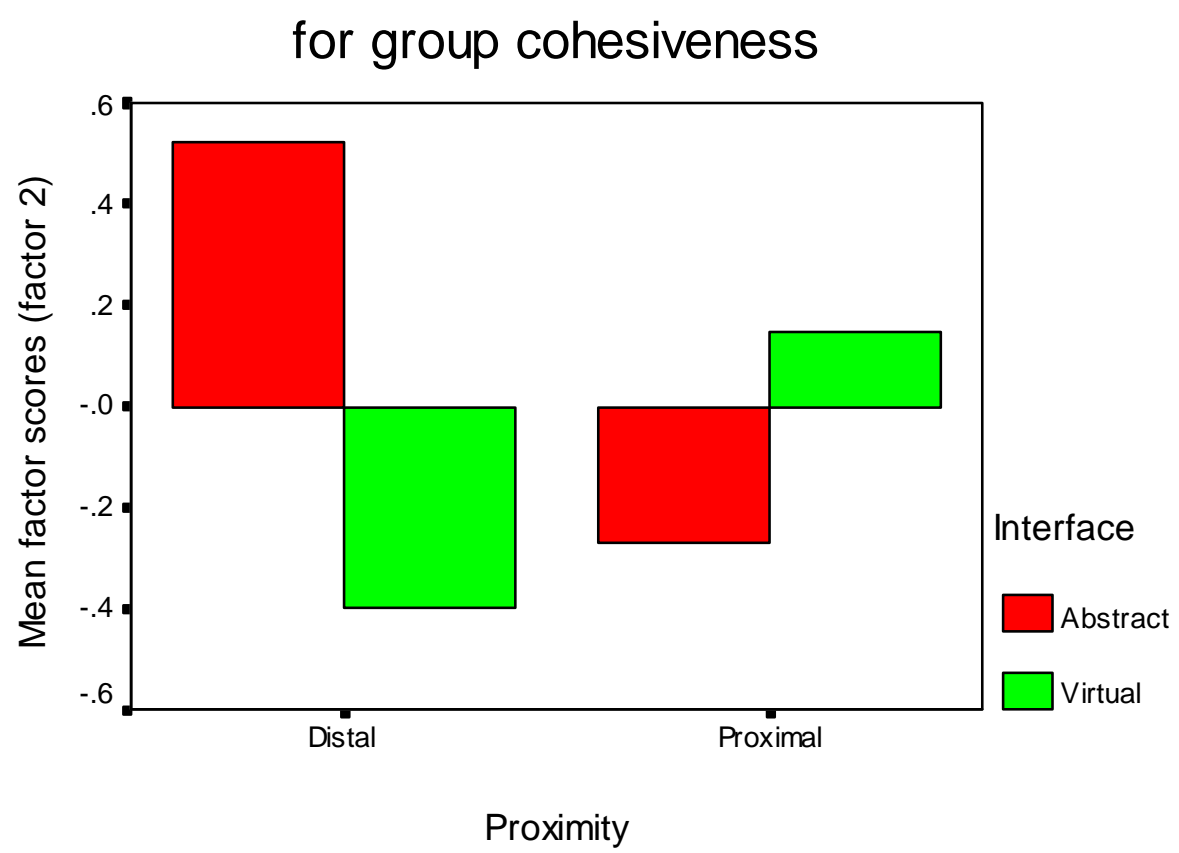

Figure 4. Mean cohesiveness scores for the experimental conditions 


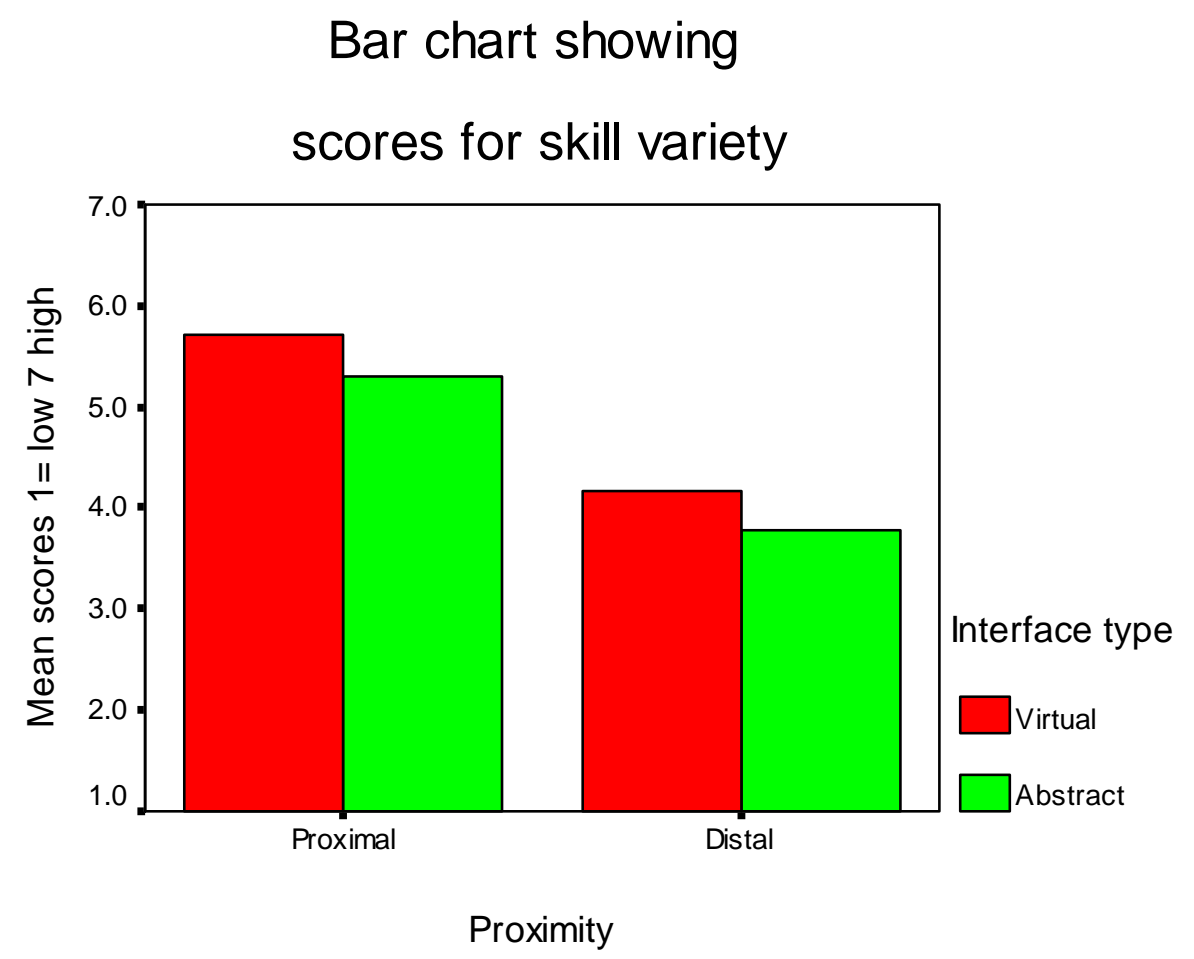

Figure 5. Mean skill variety scores for the experimental groups 
Bar chart showing scores for

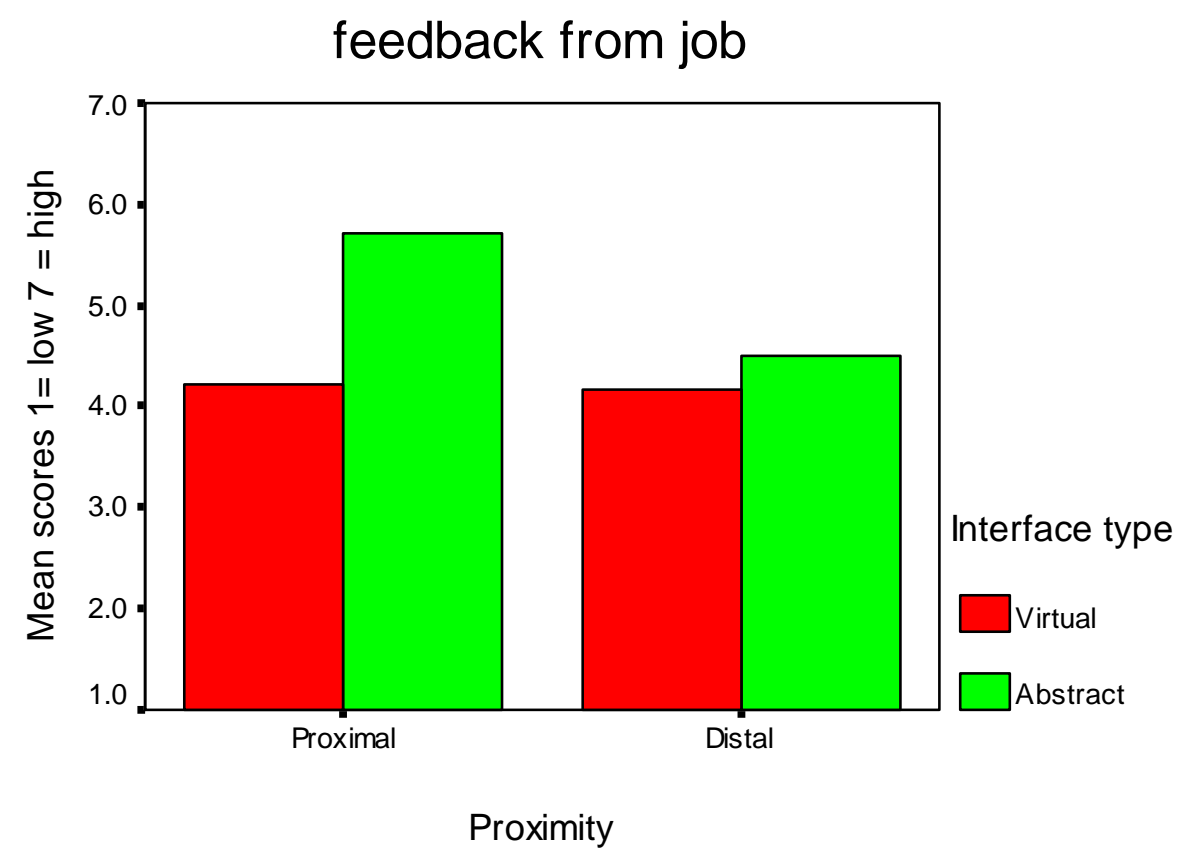

Figure 6. Mean feedback from the job scores for the experimental groups 
Bar chart showing scores for

feedback from others

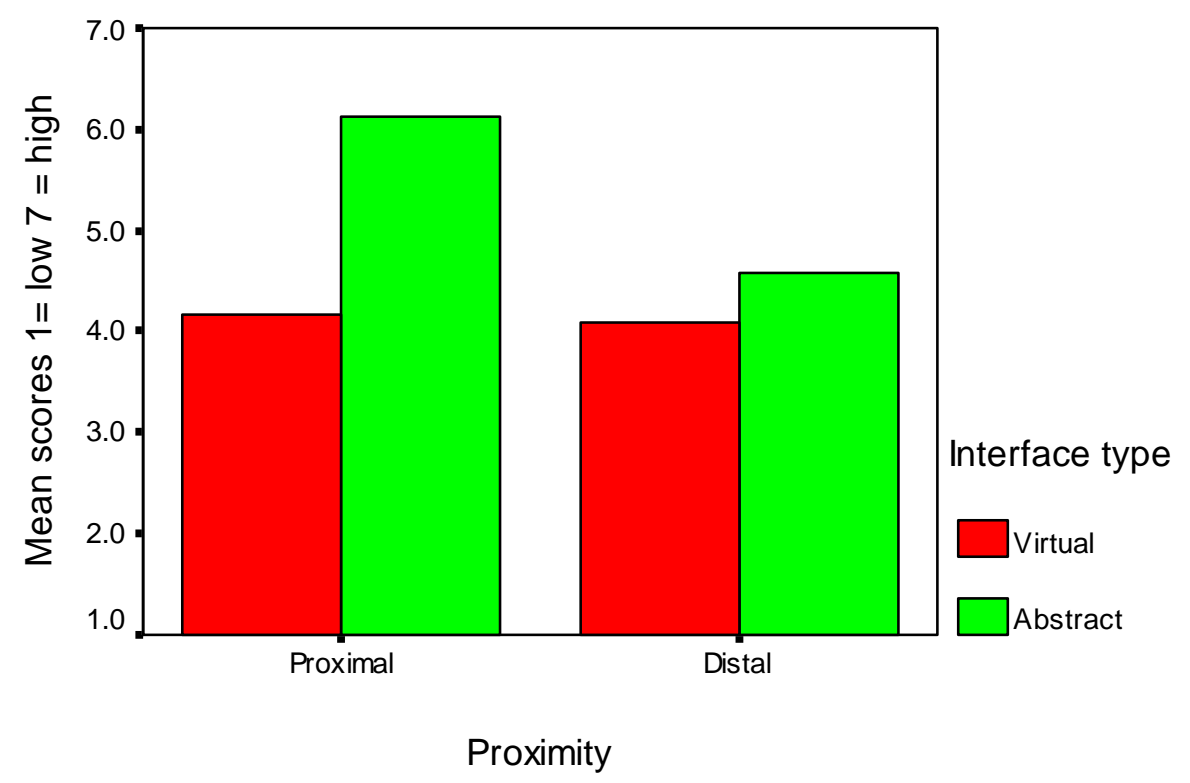

Figure 7. Mean feedback from others scores for the experimental groups 


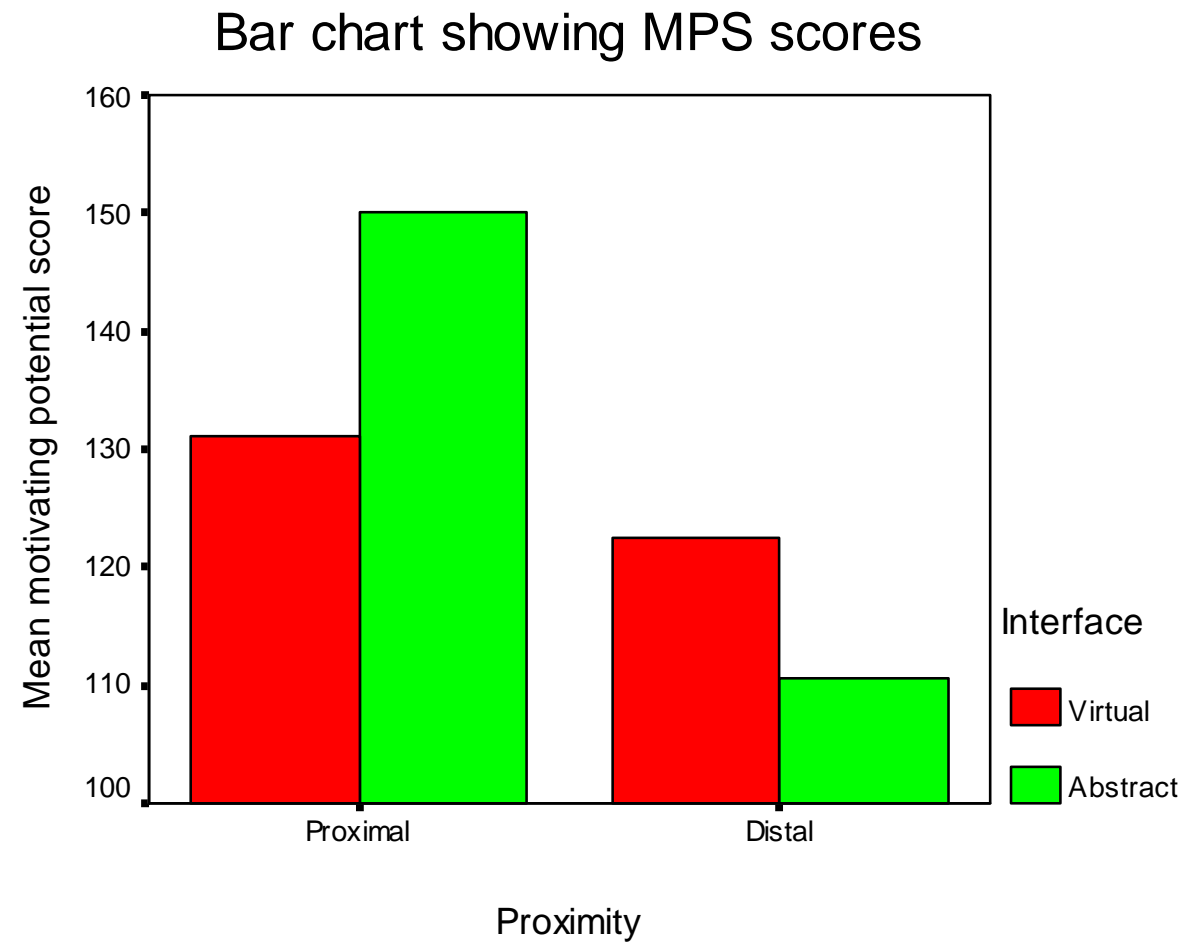

Figure 8. Mean MPS for the experimental groups 